Recepción: 09 / 04 / 2018

Aceptación: 21 / 05 / 2018

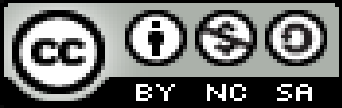

Ciencias técnicas y aplicadas

Publicación: 02 / 07 / 2018

Artículo de Investigación

\title{
Diseño y construcción de un modelo de sistema de recarga inductiva para autos eléctricos
}

\section{Design and construction of an inductive charging system model for electric cars}

\section{Projeto e construção de um modelo de sistema de carregamento indutivo para carros elétricos}

\author{
Lenin H. Sánchez-Chávez ${ }^{\text {I }}$ \\ lenin.sanchez@espoch.edu.ec \\ Celin A. Padilla-Padilla II \\ celin.padilla@espoch.edu.ec \\ Wilson J. Villagrán-Cáceres III \\ wilson.villagran@espoch.edu.ec \\ Henrry D. Zavala-Orozco IV \\ henrry.zavala@espoch.edu.ec \\ Luis F. Buenaño-Moyano ${ }^{\mathrm{V}}$ \\ lfbuenaño@espoch.edu.ec
}

Correspondencia: lenin.sanchez@espoch.edu.ec

I Ingeniero Automotriz, Facultad de Administración de Empresas, Escuela Superior Politécnica de Chimborazo, Riobamba, Ecuador.

${ }^{\text {II }}$ Magíster en Diseño Mecánico Mención en Fabricación de Autopartes de Vehículos, Master en Ingeniería de Vehículos Híbridos y Eléctricos, Diplomado Superior en Gestión del Aprendizaje Universitario, Ingeniero Automotriz, Facultad de Mecánica, Escuela Ingeniería Automotriz, Docente de la Escuela Superior Politécnica de Chimborazo, Riobamba, Ecuador.

\footnotetext{
III Magister en Matemática Básica, Diploma Superior en Gestión Educativa, Ingeniero en Electrónica y Computación, Facultad de Mecánica, Escuela Superior Politécnica de Chimborazo, Riobamba, Ecuador.

IV Ingeniero en Mantenimiento, Facultad de Mecánica, Escuela Superior Politécnica de Chimborazo, Riobamba, Ecuador.
}

${ }^{\mathrm{V}}$ Magister en Gestión del Mantenimiento Industrial, Ingeniero Automotriz, Facultad de Mecánica, Escuela Superior Politécnica de Chimborazo, Riobamba, Ecuador. 


\title{
Resumen
}

El objetivo de esta investigación es diseñar y construir un modelo de sistema de recarga inductiva para autos eléctricos, con esta alternativa no se requiere de cables para recargar las baterías puesto que el sistema de recarga inductiva es capaz de disminuir el tiempo de carga de las baterías en autos eléctricos. El proceso de recarga es automático y se inicia al posicionar el auto sobre la plataforma de recarga inductiva sin necesidad de que exista contacto entre los dos para que se inicie. La metodología implementada fue de tipo experimental y se fundamentado en el diseño y construcción de dos bobinas (emisor y receptor), la inductancia mutua de estas bobinas depende de la distancia a la que se encuentran alejadas entre sí. Conociendo los avances tecnológicos existentes en el campo automotriz concretamente en vehículos eléctricos, la recarga de baterías es un área fundamental para generar investigación en la carrera de Ingeniería Automotriz. A través de este estudio se demuestro que la tecnología del sistema de recarga inductiva en vehículos eléctricos es factible de realizar en el Ecuador y se puede convertir en un beneficio importante para los usuarios.

Palabras clave: diseño; construcción; bobina; recarga inductiva; batería.

\begin{abstract}
The objective of this research is to design and build a model of inductive recharging system for electric cars, with this alternative no cables are required to recharge the batteries since the inductive recharging system is able to reduce the battery charging time in electric cars. The recharging process is automatic and begins when positioning the car on the inductive recharge platform without the need for contact between the two to start. The implemented methodology was of experimental type and is based on the design and construction of two coils (emitter and receiver), the mutual inductance of these coils depends on the distance at which they are far from each other. Knowing the technological advances existing in the automotive field, specifically in electric vehicles, recharging batteries is a fundamental area to generate research in the Automotive Engineering career. Through this study it was demonstrated that the technology of the inductive recharging system in electric vehicles is feasible to perform in Ecuador and can be converted into an important benefit for users.
\end{abstract}

Keywords: Design; building; coil; inductive recharge; battery. 


\section{Resumo}

O objetivo desta pesquisa é projetar e construir um modelo de sistema de estações de carregamento indutivo para carros elétricos, esta alternativa não é necessária cabos para recarregar as baterias desde que o sistema indutivo de carregamento é capaz de diminuir o tempo de carregamento de baterias em carros elétricos. O processo de recarga é automático e começa ao posicionar o carro na plataforma de recarga indutiva sem a necessidade de iniciar o contato entre os dois. A metodologia experimental foi implantado e com base no desenho e construção de duas bobinas (emissor e receptor), a indutância mútua destas bobinas depende da distância que estão distantes. Conhecendo os avanços tecnológicos existentes no campo automotivo, especificamente em veículos elétricos, a recarga de baterias é uma área fundamental para gerar pesquisas na carreira de Engenharia Automotiva. Através deste estudo foi demonstrado que a tecnologia do sistema de recarga indutiva em veículos elétricos é viável de se realizar no Equador e pode ser convertida em um benefício importante para os usuários.

Palavras chave: design; construção; bobina recarga indutiva; bateria.

\section{Introducción}

En la última década el planeta ha experimentado uno de los mayores revuelos en todos los aspectos que inciden en una sociedad globalizada, dentro de los que se destaca el acelerado desarrollo tecnológico enmarcado en el mejoramiento de múltiples plataformas de servicios mediante la incorporación de sistemas informáticos inteligentes que mejoran y optimizan el tiempo del cumplimiento de las tareas cotidianas, otro de los aspectos y el más importante, es el crecimiento de la población que trasgrede en la organización y planificación adecuada acorde al crecimiento de los centros urbanos que se van desarrollando proporcionalmente con la población, tal crecimiento implica un desarrollo en obra civil, servicios básicos vías de acceso y medios de transporte. El crecimiento de zonas urbanas y la necesidad de movilización en conjunto con la oferta del mercado del campo vehicular, apuntan Granada, Arias y Sánchez (2017), han ocasionado el incremento del parque automotor de los centros urbanos y por ende el deterioro en el sistema ecológico del planeta por la contaminación existente inherente del uso de motores de combustión interna, cuya fuente de generación de energía son los combustibles fósiles, siendo su obtención y utilización incidentes de manera considerable en el deterioro del planeta. 
En la actualidad, el crecimiento del parque automotor señala Alonso (2011), requiere la necesidad de optimizar los sistemas de movilidad y disminuir la contaminación, mediante la utilización de energías alternativas a través de la incorporación de vehículos híbridos y eléctricos que minimicen el impacto ambiental, para lo cual se requiere de un proceso de investigación en sistemas inteligentes que permitan optimizar tiempos de recarga al igual que la incorporación de sistemas de recarga inductiva de modo estático, masificando la integración y el uso de vehículos eléctricos $(\mathrm{EV})$.

Con este análisis se construirá un prototipo con un sistema de recarga para autos eléctricos los cuales ya no requirieran de cables para alimentar de energía eléctrica a las baterías, debido a que este nuevo sistema inductivo, utiliza el flujo magnético de la bobina emisora y receptora, optimizando de esta manera el tiempo de recarga de las baterías. Para iniciar el proceso de manera automática, explican Villa, Sanz, Sallan y Perje (2013), se debe posicionar el vehículo sobre la plataforma de recarga inductiva, sin necesidad de que exista contacto entre las superficies de la base o emisor y el vehículo o receptor.

Para ello Kip (1967), expresa que se contará con dos bobinas (emisor y receptor), en las cuales el flujo magnético enlazante pasará de la bobina uno a la bobina dos, ubicada en el vehículo, cuya eficiencia de inducción dependerá de la distancia y la alineación a la que se encuentren dichas bobinas para que el flujo magnético sea máximo.

\section{Consideraciones teóricas}

En los últimos tiempos la teoría electromagnética, apunta Zozaya (2017), ha sido una de las herramientas primordiales para el desarrollo tecnológico como lo es el campo de las telecomunicaciones, con experimentos tales como los realizados por Nikola Tesla y su bobina, la cual estaba conformada por un transformador resonante en el que se regeneraban campos eléctricos indeseables, los cuales permitían radiar energía en todas las direcciones, demostrando de esta manera que la transferencia de energía inalámbrica era posible, sin embargo es necesario considerar el aporte que también se realiza, visto desde la perspectiva del aprovechamiento de la transferencia de energía mediante el flujo magnético, para ello Gazoni y Zotelo (2007), revelan que viene dado por:

$$
\Phi=\text { B.S. } \cos \varphi
$$


Donde B es la Intensidad de campo magnético medido en Teslas (T), S la superficie por la que atraviesa el campo magnético, medida en (m2), el Flujo magnético variará a través del espacio en función del tiempo dependiendo de la distancia a la que se encuentran las dos bobinas (transmisora y receptora), las cuales permiten recargar dispositivos que requieren fuentes de almacenamiento de carga eléctrica (baterías). Este proceso inicia cuando el flujo variante en el tiempo es captado por la bobina receptora en la cual se induce un voltaje, el cual se expresa mediante la siguiente ecuación:

$$
V=-N \frac{d \Phi}{d t}
$$

La relación anterior se conoce como la Ley de Faraday, quien fue un, físico y químico originario del Reino Unido, a quien debemos aportes científicos importantes y de gran incidencia en el desarrollo tecnológico actual, tales como el estudio sobre el diamagnetismo, la electrolisis y el estudio de mayor difusión que es la inducción electromagnética, la que demuestra que el voltaje inducido es directamente proporcional a la velocidad con la que cambia el flujo magnético que atraviesa una superficie. Es importante mencionar que el signo negativo se atribuye, y es considerada como la Ley de Lenz, la cual manifiesta que el voltaje inducido toma una polaridad contraria, la cual genera una corriente opuesta a la dirección de la velocidad de cambio del flujo magnético, continuando con la explicación de la ecuación que gobierna la Ley de Faraday se puede decir según Zozaya (2017) que la fuerza electromotriz inducida en cualquier circuito cerrado, es igual al negativo de la velocidad de cambio con respecto al tiempo del flujo magnético que atraviesa una superficie delimitada por el circuito cerrado, en donde $\mathrm{V}$ representa el voltaje inducido en el receptor, medido en voltios (Volts) resultado de realizar el análisis dimensional entre el flujo magnético, medido en webers ( $\mathrm{Wb}$ ) y el tiempo medido en segundos (Seg.), $\mathrm{N}$ representa el número de espiras que posee la bobina, y el diferencial, es la velocidad de variación con la que cambia el flujo magnético con respecto al tiempo.

Existen varios experimentos que permiten analizar la inducción electromagnética, que se describe desde la primera prueba a partir del enlace de dos bobinas mediante un anillo de hierro conectado a una fuente de alimentación, y un multímetro que permitirá medir la presencia de una corriente inducida. Una segunda experiencia, es la utilización de una espira conductora y un imán, para lo cual se conecta la espira de prueba a un multímetro, mientras que, al imán, orientando con su polo 
norte hacia la bobina se lo acerca y aleja de la espira, a una distancia adecuada en la que se pueda apreciar la acción de las líneas de campo magnético, generadas por el imán. Luego de realizar esta experiencia, se puede observar que en la bobina existe la presencia de una corriente inducida producto del movimiento del imán, dejándonos como conclusión, que la presencia de una corriente inducida en la bobina dependerá de la variación del flujo magnético debido al movimiento del que se realiza en el imán, ya que si este permanece fijo la corriente será nula. La tercera experiencia consiste en la colocación de dos bobinados frente el uno del otro, los cuales son conectados a una fuente de corriente alterna y un multímetro respectivamente, La fuente de corriente alterna es de vital importancia ya que como fue analizada en el experimento anterior, se requiere que el flujo magnético no sea constate por lo tanto debe ser variante en el tiempo, lo que permitirá, según Castaño (2008) la aparición de una corriente inducida que se aprecia en el instrumentó de medición. Cabe recalcar que el modelo de sistema de recarga inductiva que se propone en esta investigación está basado y modelado en función del tercer experimento de la inducción electromagnética.

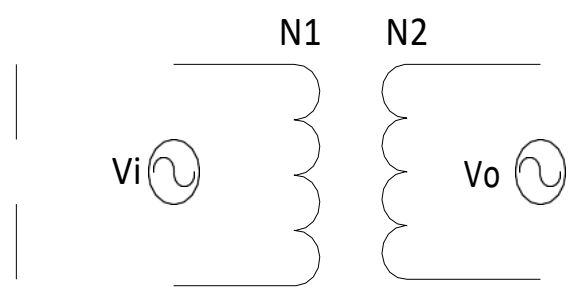

Figura 1. Bobinas Transmisora y receptora.

En la figura 1, se representa por el transformador y las bobinas tanto del emisor como del receptor, que constituyen el sistema de recarga inductiva, como se indicó en el tercer experimento, cuya relación viene dada según Gazoni y Zotelo (2007), por:

$$
\frac{V i}{V o}=\frac{N 1}{N 2}
$$

En la cual, Vi, es el voltaje de entrada aplicada en el transmisor, Vo es el voltaje en el receptor, N1 el número de espiras en la bobina transmisora y N2 el número de espiras en la bobina receptora. 
Se debe considerar, que las bobinas al no tener un núcleo que los atraviese, ni estar entrelazados, se encuentran separados una distancia determinada, lo que hará que el flujo enlazante de la bobina transmisora no atraviese en su totalidad a la bobina receptora verificando una disminución de la eficiencia de transferencia la cual mide el grado de acoplamiento, mediante la cantidad de flujo magnético presente en la bobina transmisora que genera una corriente que será inducida a la bobina receptora utilizada para la recargara de las baterías, el factor de eficiencia de transferencia viene dada por:

$$
\gamma=\frac{V o m}{V i}
$$

En donde, $\gamma$ representa la eficiencia de transferencia la cual tomara valores entre 0 y 1 , el valor de 1 representa el grado de acoplamiento ideal del flujo magnético enlazante, entre el transmisor y receptor, en el cual Vom, representa el voltaje máximo presente en la bobina receptora, y Vi el voltaje de la fuente aplicada a la bobina transmisora.

En la actualidad los vehículos eléctricos, afirma López (2015), requieren de un procedimiento eficiente de recarga sin necesidad de cables y conectores, lo cual es posible, mediante la implementación de sistemas inalámbricos de transferencia de energía o también conocida como recarga inductiva.

\section{Materiales y métodos}

El método utilizado para esta investigación es el método experimental, dado que se manipulo la variable en estudio, al someterse a pruebas diversas, controlando para en este caso el voltaje presente en el receptor a través del posicionamiento a diferentes distancias, entre la bobina receptora y transmisora ubicadas estratégicamente en el piso, y en el bastidor del vehículo de prueba. El experimento realizado fue de tipo confirmatorio, ya que se analizó el efecto que experimenta el voltaje inducido en el circuito receptor en función de la distancia establecida entre las bobinas transmisora y receptora, respectivamente. En base al análisis establecido, se definió el voltaje que aparece en el receptor como la variable dependiente y a la distancia establecida entre los bobinados transmisora y receptora, como la variable independiente, es importante indicar que no se consideró para esta experiencia ninguna variable adicional externa u extraña que incidiera durante el desarrollo de esta experiencia. El diseño del experimento estuvo basado en el análisis 
del voltaje que se presente en el receptor en función de la distancia y la modelación de una ecuación matemática que permitió predecir las respuestas futuras acorde a la experimentación, teniendo en consideración que el limitante primordial del experimento está dado por la distancia de separación de las bobinas. Para implementar el experimento se tomó en consideración:

- Comprender el problema y establecer los objetivos.

- Identificar los factores que inciden en el desarrollo del experimento, como los posibles valores que tomen las variables, y buscar entre dichos valores los parámetros relevantes para el desarrollo del sistema.

- Establecer una estrategia y planificar un algoritmo adecuado para implementar el plan de experimentación.

- Aplicar los experimentos y obtener los valores que permitirán establecer los requerimientos necesarios para el desarrollo y correcto funcionamiento del sistema.

- Interpretar los resultados a través de la construcción de una ecuación matemática que permita predecir el comportamiento de los parámetros que inciden en el sistema de modelo de recarga inductiva, para elaborar las conclusiones correspondientes, las cuales deberán según Miranda e Iglesias (2015), ser cuidadosamente revisadas, para en caso de no ser pertinentes o acordes con lo planteado, se repita nuevamente el experimento.

Una vez realizado el diseño e implantación del experimento, conjuntamente con la obtención de los valores establecidos para los parámetros que conforman el sistema de recarga inductiva, se procedió a la planeación de las actividades para la construcción del sistema de recarga inductiva, el cual se encuentra enmarcado y respaldado en el método conformado por las siguientes etapas:

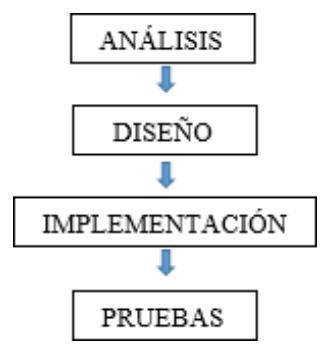

Figura 2. Método aplicado para la construcción e implementación del sistema. 


\section{Análisis}

Durante el desarrollo de esta etapa se recopilo toda la información necesaria referente al tema de investigación, previa una detallada revisión bibliográfica de textos, catálogos, manuales, equipos de medición y pruebas similares realizadas en otros experimentos que permitieran sustentar el diseño y construcción de los subsistemas, módulos, partes y piezas necesarios que conforman el sistema de recarga inductiva, para alcanzar los objetivos planteados. El siguiente diagrama de bloques, muestra los bloques principales, los procesos y los requerimientos que deben conformar el sistema y su interacción (Villa, 2015).

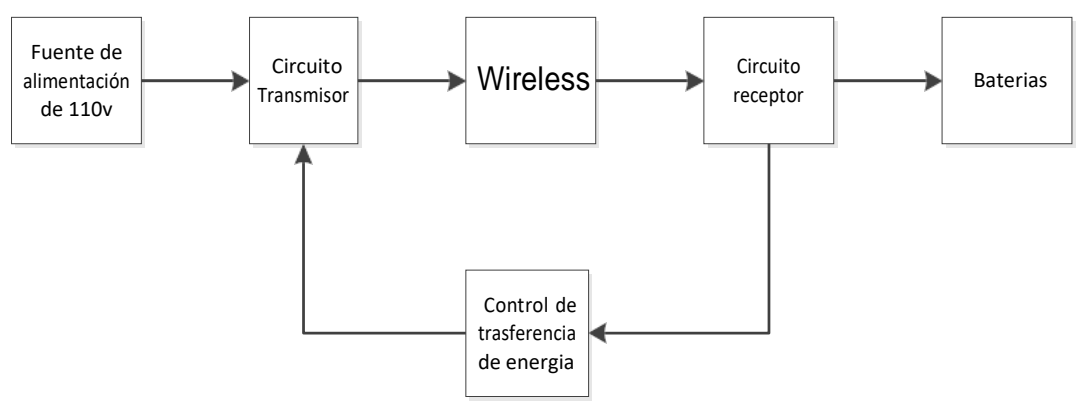

Figura 3. Esquema general del sistema de recarga inductiva.

\section{Diseño}

Esta etapa consistió en adquirir los requerimientos necesarios para cada uno de los módulos definidos en la etapa de análisis, de igual forma los procesos que realizaron cada elemento para el adecuado funcionamiento del modelo de recarga inductiva, procediendo a diseñar cada uno de los sistemas y subsistemas eléctricos y electrónicos que conformaron el modelo de recarga inductiva, de forma semejante se realizó la construcción de los elementos mecánicos para su empotramiento en el piso y el bastidor en el vehículo de prueba, lo que permitió su correcto funcionamiento y la recolección adecuada de los datos. El siguiente diagrama de flujo permite visualizar de manera sistemática las etapas a las cuales fueron sometidas cada uno de los módulos que conforman el sistema durante su diseño, teniendo que considerar una bifurcación, la cual garantiza la validación de los parámetros que utilizan los procesos, para alcanzar los objetivos planteados (Villagrán, 2015). 


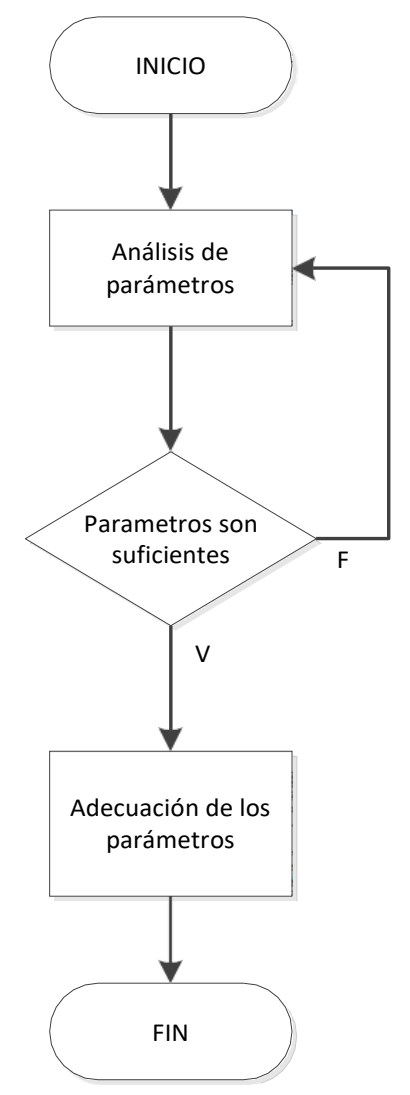

Figura 4. Diagrama de flujo para el control del diseño.

Cada módulo que conforma el sistema de recarga inductiva realiza un proceso determinado, estos procesos requieren ser controlados para garantizar la estabilidad del sistema, y su correcto funcionamiento. El control y monitoreo de los procesos se realiza por medio del uso de un microcontrolador, mediante la construcción un circuito de control electrónico para el sistema de recarga inductiva, en función de los requerimientos del sistema, para este caso por sus prestaciones y potencialidades, se consideró al microcontrolador Arduino mega (2015), los cuales conciben una alternativa adecuada para desarrollo del sistema, el cual posee 54 pines digitales de entrada y salida, además 16 entradas analógicas, un cristal oscilador (CLK) de $16 \mathrm{MHz}$, con un voltaje de operación, el cual está definido en el intervalo de 7 a 12 voltios como máximo. Este sistema electrónico se encargará del control y monitorio del flujo energético hacia las baterías, mostrando mediante una interface gráfica, los datos generados en el sistema como también el nivel de carga de las en las mismas. En el siguiente diagrama de bloques desglosa de manera detallada los subsistemas que intervienen garantizando el control electrónico adecuado del sistema (Mojica, Cuellar y Medina, 2015). 


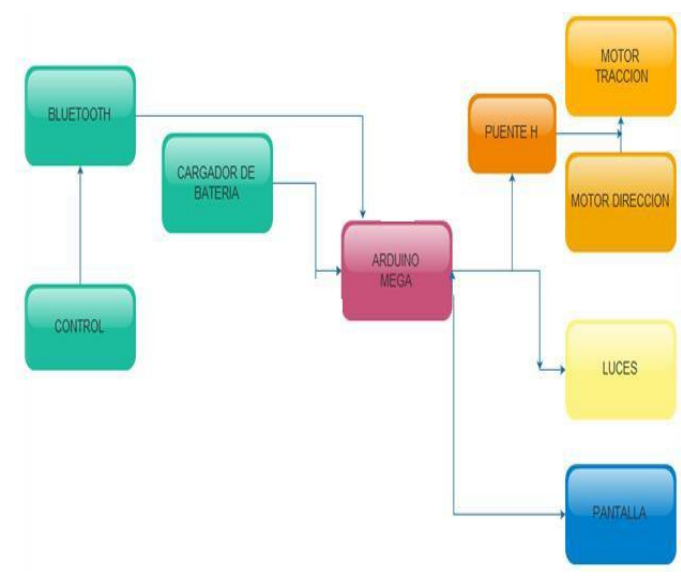

Figura 5. Esquema de la Unidad de Control.

El tipo de recarga inductiva, es denominada recarga por resonancia debido a que la carga se realiza sin contacto físico de las bobinas. El diagrama siguiente muestra los elementos que interactúan en la bobina emisora.

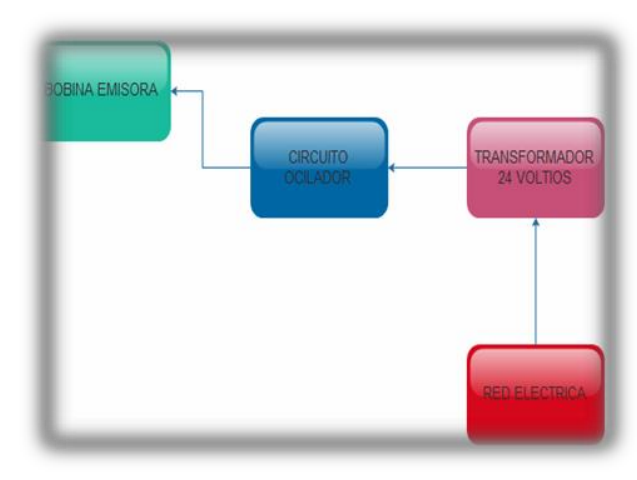

Figura 6. Esquema de la bobina del emisor.

\section{Implementación}

En la etapa de implementación se analizan varios aspectos que incidirán en el adecuado funcionamiento del sistema, es una de las etapas de mayor importancia ya que en ella se plasmara los componentes que darán vida al sistema, por lo cual requieren de una adecuada planificación ante y durante su ejecución. En la etapa de implementación se debe tener en consideración los recursos, materiales, los estados de los equipos etc. Haciendo referencia a la adecuada calibración y funcionamiento de los equipos con los cuales se elaboran los compontes. Se consideraron aspectos relevantes y acciones de contingencia que permiten sobrellevar imprevistos que se hacen presentes durante la construcción y desarrollo de los componentes y subsistemas, se consideró los 
procesos adecuados, acorde al cumplimiento y avance de las tareas previamente planificadas, avaluando que hacemos y como lo hacemos. Es importante destacar que a medida que se ejecutan las tareas planificadas, estas deben ser ajustadas y evaluadas, mediante pruebas de verificación, manejando un control de eficacia, lo cual permite continuar con el desarrollo de otras tareas o corregir en su momento alguna eventualidad que surja. Se debió realizar una revisión general de cada uno de los elementos que conformaran el sistema, para que en el momento de su montaje e incorporación no se tengan o se minimicen los inconvenientes, es necesario anexar acciones correctivas y preventivas que garanticen el desarrollo de cada una las etapas en las que se construyan los componentes y subsistemas, los resultados obtenidos deben ser analizados y evaluados, verificando si son coherentes con los objetivos planteados en la etapa de análisis, caso contrario deberemos retomar alguna de las etapas anteriores para su corrección oportuna, previo al montaje total del sistema (Chapman, 2015).

La etapa de validación del software con el que cuenta el sistema debe tener un tratamiento especial, ya que cualquier falla de lógica, puede ocasionar inconvenientes, y por lo tanto afectar el adecuado funcionamiento del sistema. El paradigma aplicado para el desarrollo del software es el paradigma secuencial lineal o en cascada, ya que es un adecuado para el desarrollo de software en proyectos con bajo proceso de datos y presupuesto limitado. Cada etapa dependerá de la anterior por lo que el paradigma tiene su limitación en el sentido de que cada etapa debe ser concluida de manera adecuada ya que en caso de no resolver una de ellas no se podrá continuar con las demás, pero es justo también resaltar la que este modelo o paradigma se acopla de manera adecuada a nuestro sistema ya que permite incorporar de una manera precisa y clara los requerimientos del sistema, siguiendo la siguiente secuencia (López, 2015). En primera instancia se necesita realizar un análisis de requerimientos del sistema, definir las variables de entrada, salida y las operaciones que se van a desarrollar con ellas, en este caso el posicionamiento adecuado de las bobinas, el voltaje presente en las bobinas, el nivel de carga de las baterías, variables para activación de los servo motores y variables auxiliares para el cambio de las mismas en el seguidor de línea. La etapa de diseño en la cual se desarrolló el algoritmo que se desea implementar para el adecuado funcionamiento del sistema, La etapa de implementación que a diferencia de la implantación descrita anteriormente, cosiste en la codificación del algoritmo diseñado en la sintaxis correspondiente al lenguaje de programación, Visual C, luego de realizada la compilación, se procedió con la compilación del 
programa, corrigiendo fallas referentes a la sintaxis de palabras reservadas, operadores y estructuras de control las cuales deben ser correctamente detalladas, las pruebas sobre la lógica del programa se la van realizado de manera secuencial verificando cada parámetro de los utilizados para su ejecución, durante esta etapa se detectan fallas que tienen que ser corregidas oportunamente, ya que el hardware y software del sistema deben funcionar de manera sincronizada, lo que garantiza el óptimo funcionamiento del módulo inteligente del sistema.

El siguiente diagrama de bloques, muestra los componentes y módulos del sistema de recarga inductiva que son construidos y montados para su adecuado funcionamiento, acorde al cumplimiento de las actividades planificadas y la validación de las pruebas realizadas, que permiten alcanzar los objetivos planteados.

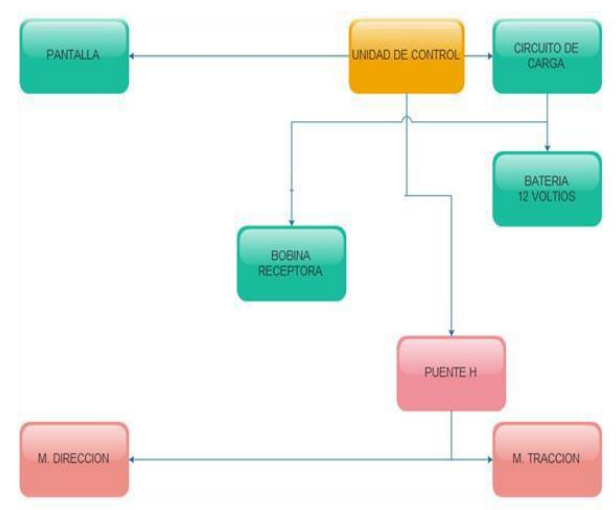

Figura 7. Diagrama de bloques del modelo de recarga inductiva.

En el modelo de sistema de recarga inductiva, para su correcto funcionamiento cuenta con los siguientes circuitos:

- Circuito oscilador de $130 \mathrm{~Hz}$

- Circuito rectificador.

- Circuito de carga de baterías.

- Puente H para el control de los motores de dirección y tracción.

- Placa de control central.

- Circuito para visualización de carga.

- Circuito seguidor de línea 


\section{Pruebas}

Una vez finalizadas las etapas de diseño y construcción se procedió al montaje del modelo de recarga inductiva para proceder a realizar las pruebas de funcionamiento, para esta experiencia se consideró a las bobinas transmisora y receptora con igual número de espiras (100y un diámetro de $3 \mathrm{~cm}$ ), procediendo con la aplicación del plan de experimentación de igual manera diseñado y validado, mediante su aplicación se pudo obtener los resultados de las mediciones del voltaje presente en la bobina receptora, para proseguir con su tabulación y procesamiento. La siguiente tabla muestra las mediciones de voltaje realizadas en la bobina receptora ubicada estratégicamente en el bastidor del vehículo, mediante la utilización de un multímetro se realizaron las lecturas de los voltajes a ciertas distancias, las cuales dependen de la calibración de un mecanismo que permite variar la distancia de la bobina transmisora hacía en bastidor del vehículo (cada $5 \mathrm{~mm}$ ). Es importante mencionar que se debe tener en consideración una alerta sonara, la cual nos advierte el alineamiento adecuado de las bobinas, para que el flujo magnético sea máximo a medida que se varié la altura para realizar la siguiente medición. Se elaboró una hoja electrónica para registrar los datos de las lecturas realizadas de voltaje y distancia, como también el cálculo del voltaje promedio y el factor de eficiencia de transferencia en cada una de las mediciones correspondientes. Los parámetros iniciales medios con los que cuenta en sistema antes de las pruebas son:

- $\quad$ Voltaje de red $\mathrm{Vi}=110 \mathrm{~V}, 60 \mathrm{~Hz}$

- Resistencia de la bobina transmisora $9,78 \mathrm{~K} \Omega$

- Resistencia de la bobina receptora $9,97 \mathrm{~K} \Omega$

Se realizaron ocho mediciones de voltaje para cada distancia, definidas en el intervalo de 0 hasta $40 \mathrm{~mm}$, repitiendo la lectura de voltaje en el receptor, cada $5 \mathrm{~mm}$, luego de realizar las mediciones correspondientes a la distancia estipulada, se procedió con el cálculo de un voltaje promedio y el factor de eficiencia de transferencia, correspondiente en cada medición. 
Tabla 1. Resultados de mediciones de voltaje presente en el circuito receptor

\begin{tabular}{|c|c|c|c|c|c|c|}
\hline 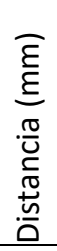 & $\begin{array}{l}\sum_{7} \\
\frac{\pi}{\pi} \\
\frac{\pi}{0} \\
>\end{array}$ & \begin{tabular}{l}
$\Sigma$ \\
\multirow{2}{*}{} \\
$\frac{0}{\pi}$ \\
$\frac{\pi}{0}$ \\
$>$
\end{tabular} & $\begin{array}{l}\sum \\
m \\
\frac{0}{\pi} \\
\frac{\pi}{0} \\
>\end{array}$ & $\begin{array}{l}\Sigma \\
\pm \\
\frac{0}{\pi} \\
\frac{\pi}{0} \\
>\end{array}$ & 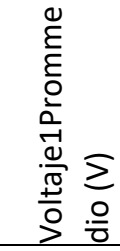 & 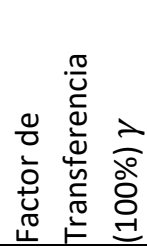 \\
\hline 0 & 50,5 & 51,6 & 51,7 & 51,6 & 51,4 & 46,68 \\
\hline 5 & 24,8 & 24,9 & 25 & 24,8 & 24,9 & 22,61 \\
\hline 10 & 16,6 & 16,4 & 16,5 & 16,6 & 16,5 & 15,02 \\
\hline 15 & 11,4 & 11,5 & 11,6 & 11,5 & 11,5 & 10,45 \\
\hline 20 & 9,1 & 9,2 & 9,1 & 9,3 & 9,2 & 8,34 \\
\hline 25 & 7,2 & 7,1 & 7,3 & 7,2 & 7,2 & 6,55 \\
\hline 30 & 5,2 & 5,1 & 5,3 & 5,2 & 5,2 & 4,73 \\
\hline 35 & 4,3 & 4,2 & 4,4 & 4,3 & 4,3 & 3,91 \\
\hline 40 & 3,4 & 3,3 & 3,5 & 3,4 & 3,4 & 3,09 \\
\hline
\end{tabular}

\section{Resultados y discusión}

Luego de aplicar el experimento y de realizadas las pruebas correspondientes se puede apreciar que la eficiencia de transferencia de energía del transmisor al receptor no es del $100 \%$ efectiva, ya que el voltaje que aparece en la bobina receptora va decayendo a medida que aumenta la distancia de separación entre los bobinados transmisor y receptor, lo que denota que el factor de transferencia disminuye de forma similar, con la distancia, es decir variara con la altura a la que se encuentra la bobina receptora ubicada el bastidor del vehículo de prueba, y el voltaje presente en el mismo receptor. Con las lecturas obtenidas se puede apreciar analizando la gráfica, mostrada en la figura 8. En la que se considera $\operatorname{Vo}(d)$, como una función de voltaje vs distancia, en la cual el voltaje está medido en voltios y la distancia en milímetros, es decir el voltaje presente en el receptor en función de la distancia, mantiene tiene un comportamiento de tipo decreciente, el cual puede apreciarse en la siguiente gráfica. 


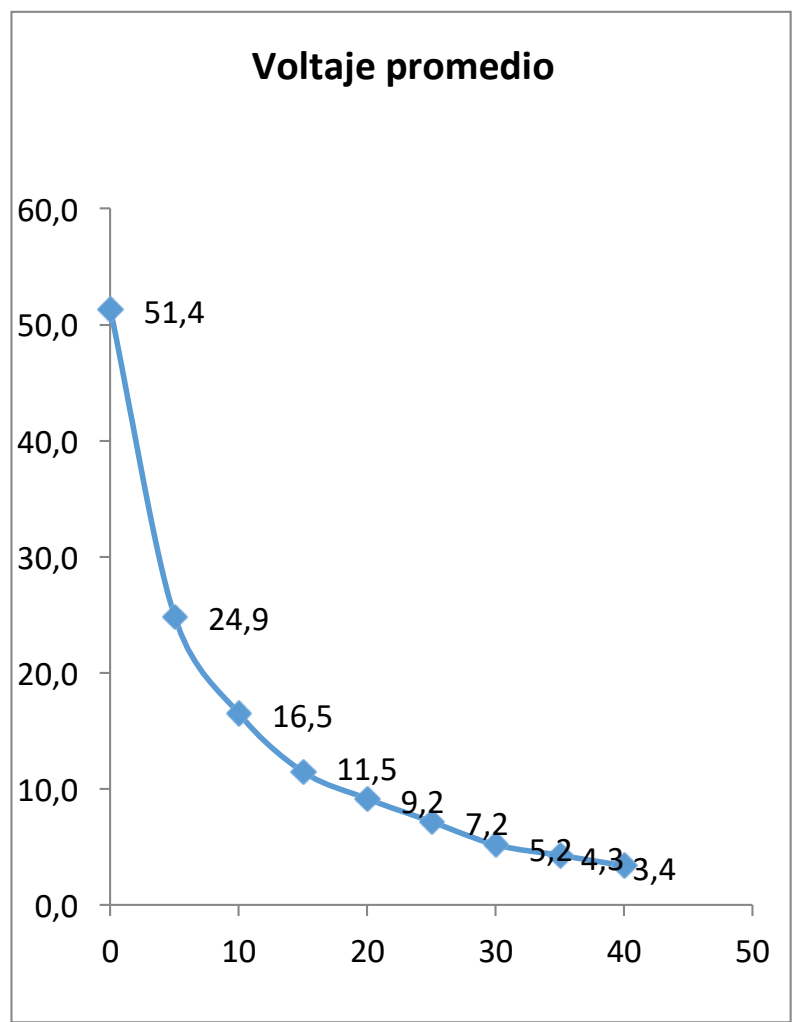

Figura 8. Grafica de voltaje promedio del receptor VS distancia.

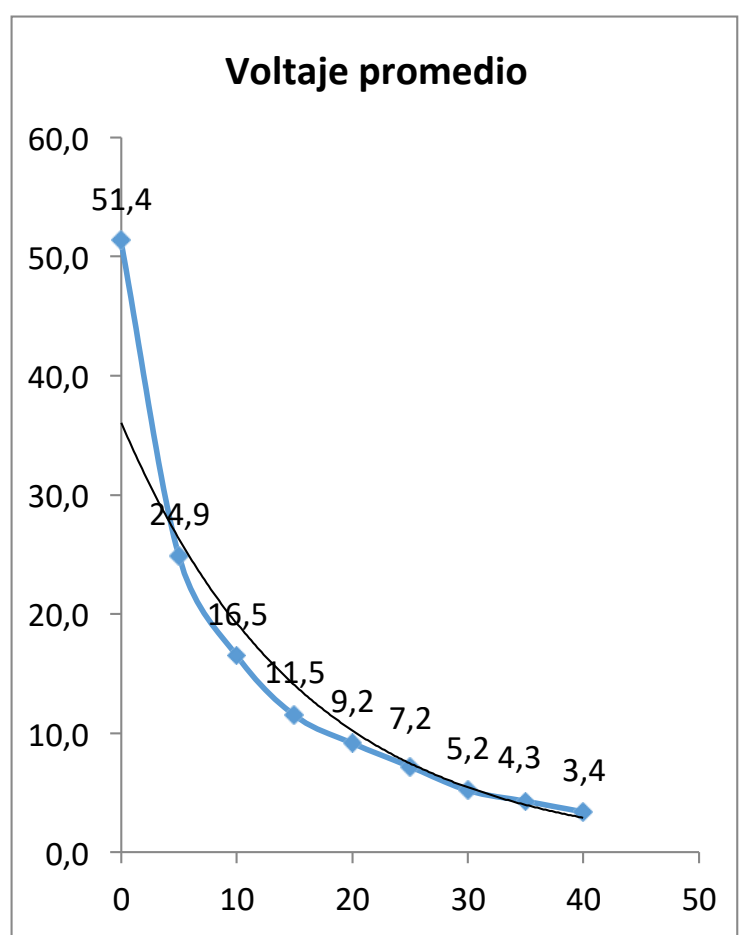

Figura 9. Línea de tendencia del voltaje promedio presente en el receptor. 
Luego de realizar la gráfica de las lecturas del voltaje obtenidas en el receptor se procedió con el trazado de la línea de tendencia presente en el voltaje de la bobina receptora, como se puede apreciar en la figura 9. Mediante la interpolación de los datos del voltaje presente el receptor, se realiza el ajuste aproximado de la curva en la que se puede observar el comportamiento de tipo exponencial del voltaje presente en el sistema el cual sufre un decaimiento en función de la distancia, una vez que se han procesado e interpretado los datos se puede describir la ecuación matemática que modela el comportamiento del voltaje inducido presente en el sistema, la cual está dada por:

$$
V o=36,053 e^{-0.063 d}
$$

En la que Vo, representa el voltaje presente en el receptor y "d", la distancia de separación definida entre la bobina del transmisor y receptor, respectivamente.

\section{Conclusiones}

Se diseñó e implemento un plan estratégico que permite desarrollar el experimento de inducción electromagnética de manera adecuada, para realizar las mediciones requeridas, facilitando la obtención de los valores necesarios que permitieron modelar la ecuación matemática que representa el comportamiento del sistema.

Se construyó dos bobinas de $3 \mathrm{~cm}$ de diámetro y 100 espiras tanto para el circuito emisor y receptor respectivamente, permitiendo generar el voltaje inducido para la recarga de las baterías, el cual dependerá de la distancia de separación existentes entre ambas bobinas.

Se diseñó el sistema inteligente que puede detectar la posición correcta entre el bobinado emisor y receptor (Línea de acción perpendicular), haciendo que el flujo enlazante sea máximo, Garantizando una óptima recarga de las baterías,

Se diseñó y construyó un sistema de control electrónico para el sistema de recarga inductiva, que impide que la temperatura en las baterías sea elevada, preservando la vida útil de las mismas.

Se realizaron las pruebas correspondientes al experimento en las cuales se pudo apreciar el comportamiento que tiene el voltaje del receptor con respecto a la distancia de separación entre las bobinas (transmisora y receptora). 
Se comprobó experimentalmente que la implementación de un sistema de recarga inductiva es factible, lo que permitirá desarrollar investigaciones referentes a la implementación de electrolineras en estacionamientos públicos y estaciones de servicio.

Fomentar un estudio mediante la utilización de voltajes mayores a 110 y una disminución en el número de espiras en la bobina del transmisor para de esta manera elevar el Voltaje, optimizando el tiempo de recarga inductiva.

Iniciar con estudios de factibilidad y propuestas para la implementación de estaciones fijas de recarga al igual que la construcción e implementación de carriles inductivos en carreteras para la recarga de las baterías en vehículos eléctricos en nuestro país.

\section{Referencias Bibliográficas}

Alonso, M. (2011). El Vehículo Eléctrico, desafíos tecnológicos, infraestructuras y oportunidades de negocios. Barcelona: Nova Era Barcelona.

ARDUINO, M. $\quad$ E. G. A. $2560 . \quad$ (2017) [Online]. https://www.arduino.cc/en/Main/ArduinoBoardMega2560\#

Castaño, A. (2008). UNNE - Facultad de Ingeniería. [Online]. http://ing.unne.edu.ar/pub/fisica3/170308/teo/teo5.pdf

Chapman, S (2012). Máquinas eléctricas, 5th ed. México: McGraw Hill.

Gazoni, R y Zotelo, C (2007). "Estudio de la variación de campo magnético debido a corrientes inducidas". APANTALLAMIENTO ELECTROMAGNETICO.

Granada, M; Arias, A y Sánchez, J. (2017). Vehículos eléctricos, energía y movilidad. Pereira: Editorial de la Universidad Tecnológica de Pereira.

Kip A. (1967). Fundamentos de Electricidad y Magnetismo. Madrid, España: Catillo S. A.

López, J. (2015). Vehículos híbridos y eléctricos: diseño del tren propulsor. Madrid: Sección de Publicaciones de la Escuela Técnica Superior de Ingenieros Industriales.

Miranda, J y Iglesias, N. (2015). "Las infraestructuras de recarga y el despegue del vehículo eléctrico'". Observatorio Medioambiental, Diciembre. 
Villa, J (2009). Sistemas de transferencia de energía para vehículos eléctricos mediante acoplamiento inductivo.

Villa, J; Sanz J; Sallan J y Perié, J. (2013). "Inductive Battery Charging System for Electric," EVS27 International Battery, Hybrid and Fuel Cell Electric Vehicle Symposium.

Villagrán W. (2015). Utilización de la Transformada de Laplace como herramienta metodológica en el análisis de circuitos eléctricos, Marzo.

Zozaya, A. (2017). Apuntes de Teoría Electromagnética.: Universidad de Carabobo. 